\title{
Lobate and flow-like features on asteroid Vesta
}

\author{
David A. Williams ${ }^{\mathrm{a}, *}$, David P. O'Brien ${ }^{\mathrm{b}}$, Paul M. Schenk ${ }^{\mathrm{c}}$, Brett W. Denevi ${ }^{\mathrm{d}}$, Uri Carsenty ${ }^{\mathrm{e}}$, \\ Simone Marchi ${ }^{f}$, Jennifer E.C. Scully ${ }^{g}$, Ralf Jaumann ${ }^{\text {e }}$, Maria Cristina De Sanctis ${ }^{\mathrm{h}}$, \\ Ernesto Palomba ${ }^{\mathrm{h}}$, Eleonora Ammannito ${ }^{\mathrm{h}}$, Andrea Longobardo ${ }^{\mathrm{h}}$, Gianfranco Magni ${ }^{\mathrm{h}}$, \\ Alessandro Frigeri ${ }^{\mathrm{h}}$, Christopher T. Russell ${ }^{\mathrm{g}}$, Carol A. Raymond ${ }^{\mathrm{i}}$, Thomas M. Davison ${ }^{\mathrm{j}}$, \\ the Dawn Science Team
}

\footnotetext{
a School of Earth and Space Exploration, Arizona State University, Tempe, AZ 85287-1404, USA

b Planetary Science Institute, Tucson, AZ, USA

${ }^{\mathrm{c}}$ Lunar and Planetary Institute, Houston, TX, USA

d Applied Physics Laboratory, Johns Hopkins University, Laurel, MD, USA

e German Aerospace Center (DLR), Berlin, Germany

${ }^{\mathrm{f}}$ NASA Lunar Science Institute, Boulder, CO, USA

${ }^{g}$ Institute of Geophysics and Planetary Physics, University of California, Los Angeles, Los Angeles, CA, USA

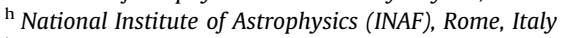

i NASA Jet Propulsion Laboratory, California Institute of Technology, Pasadena, CA, USA

j Department of the Geophysical Sciences, University of Chicago, Chicago, IL, USA
}

\section{A R T I C L E I N F O}

Article history:

Received 19 December 2012

Received in revised form

10 June 2013

Accepted 19 June 2013

Keywords:

Asteroids

Vesta

Dawn

Impact cratering

\begin{abstract}
A B S T R A C T
We studied high-resolution images of asteroid Vesta's surface ( $\sim 70$ and $20-25 \mathrm{~m} /$ pixel) obtained during the High- and Low-Altitude Mapping Orbits (HAMO, LAMO) of NASA's Dawn mission to assess the formation mechanisms responsible for a variety of lobate, flow-like features observed across the surface. We searched for evidence of volcanic flows, based on prior mathematical modeling and the well-known basaltic nature of Vesta's crust, but no unequivocal morphologic evidence of ancient volcanic activity has thus far been identified. Rather, we find that all lobate, flow-like features on Vesta appear to be related either to impact or erosional processes. Morphologically distinct lobate features occur in and around impact craters, and most of these are interpreted as impact ejecta flows, or possibly flows of impact melt. Estimates of melt production from numerical models and scaling laws suggests that large craters like Marcia ( $\sim 60 \mathrm{~km}$ diameter) could have potentially produced impact melt volumes ranging from tens of millions of cubic meters to a few tens of cubic kilometers, which are relatively small volumes compared to similar-sized lunar craters, but which are consistent with putative impact melt features observed in Dawn images. There are also examples of lobate flows that trend downhill both inside and outside of crater rims and basin scarps, which are interpreted as the result of gravity-driven mass movements (slumps and landslides).
\end{abstract}

(c) 2013 Elsevier Ltd. All rights reserved.

\section{Introduction}

The asteroid Vesta is of great interest because Earth-based telescopic spectroscopy suggests that it has a basaltic to ultramafic composition (McCord et al., 1970; Binzel et al., 1997; Gaffey, 1997; Thomas et al., 1997; De Sanctis et al., 2012), which matches closely with that of the howardite-eucrite-diogenite (HED) basaltic achondrite meteorites. The presence of basaltic compositions and textures in the HEDs (e.g., McSween et al., 2011; McSween et al., 2013 and references therein) suggest that basaltic lava flows once extruded onto

\footnotetext{
* Corresponding author. Tel.: +1 480965 7029; fax: +1 4809658960 .

E-mail address: David.Williams@asu.edu (D.A. Williams).
}

Vesta's surface (e.g., Wilson and Keil, 1996) or alternatively were derived from the crystallized remnants of a global magma ocean (Righter and Drake, 1997; Ruzicka et al., 1997; Warren, 1997), and that Vesta must have differentiated into a crust, mantle, and core (e.g., Keil, 2002; McSween et al., 2011). In addition, Vesta's location in the main asteroid belt, prior observations by the Hubble Space Telescope (Thomas et al., 1997), the nature of howardites (i.e., impact breccias: see McSween et al., 2011 and references therein), and spacecraft observations of other asteroids (e.g., Sullivan et al., 2002) all suggest that Vesta should have a heavily cratered surface, and contain resulting impact-related flow features. Thus, among the goals of NASA's Dawn Mission to Vesta (Russell et al., 2012) has been to search for and identify any flows or lobate, flow-like features, and to assess what geologic processes might have produced them. 
In this paper we report results from a review of images obtained during Dawn's High- and Low-Altitude Mapping Orbits (HAMO, LAMO), which cover over $\sim 85 \%$ of the surface at spatial resolutions of $\sim 70$ and $20-25 \mathrm{~m} /$ pixel, respectively. Our goal was to identify lobate features morphologically consistent with flows, and to identify the geologic process(es) likely to have produced these flow-like features. As you will read, the source of most of Vesta's flow-like features appears to be impact related, and so we also report results from estimates of melt production from numerical models and scaling laws to assess the likelihood of impact melts forming on Vesta.

\section{Background}

\subsection{Impact-derived lobate flows}

Impact-related flow features include ballistically-emplaced deposits of impact ejecta (i.e., ballistic sedimentation), debris flows composed of impact materials, surficial flows of impact melts, and mass movements derived from crater wall material and upslope accumulations impact debris (see e.g., Osinski et al., 2011). These features are common on Mercury, Venus, the Moon, and Mars (Dence, 1971; Gault, 1974; Howard and Wilshire, 1975; Carr et al., 1977; Melosh, 1989; Barlow, 2005). Based on previous spacecraft observations of the smaller asteroids, e.g., 951 Gaspra and 243 Ida by the Galileo spacecraft (Carr et al., 1994; Sullivan et al., 2002); 433 Eros by the NEAR spacecraft (Chapman et al., 2002; Sullivan et al., 2002); and 21 Lutetia by the Rosetta spacecraft (Massironi et al., 2012), impact craters and their ejecta deposits were expected to be commonplace on Vesta, with impact craters at all size scales and degrees of degradation, including rayed craters.

\subsection{Impact melts}

Impact melts include flows, sheets, and ponds of partially- to completely-melted target rock produced from the heat of an impact event. Most impact melts settle on impact crater floors, although some are ejected from the crater during the excavation stage, or pushed up and over the crater rim during the modification stage, followed by accumulation in topographic lows (e.g., Howard and Wilshire, 1975; Hawke and Head, 1977; Osinski et al., 2011). Morphologically impact melts can appear similar to some types of volcanic flows (i.e., lobate lava flows, sheet flows, and lava ponds: Howard and Wilshire, 1975; Hawke and Head, 1977; Bray et al., 2010; Carter et al., 2012; Denevi et al., 2012), although their source regions are traceable to impact craters rather than volcanic vents. Some of the highest resolution Lunar Reconnaissance Orbiter Camera-Narrow Angle Camera (LROC-NAC) images, however, show that lunar impact melts can have a highly variable texture, from smooth to rough at the meter scale to very rough at the decimeter scale (Carter et al., 2012). Lunar impact melt flows
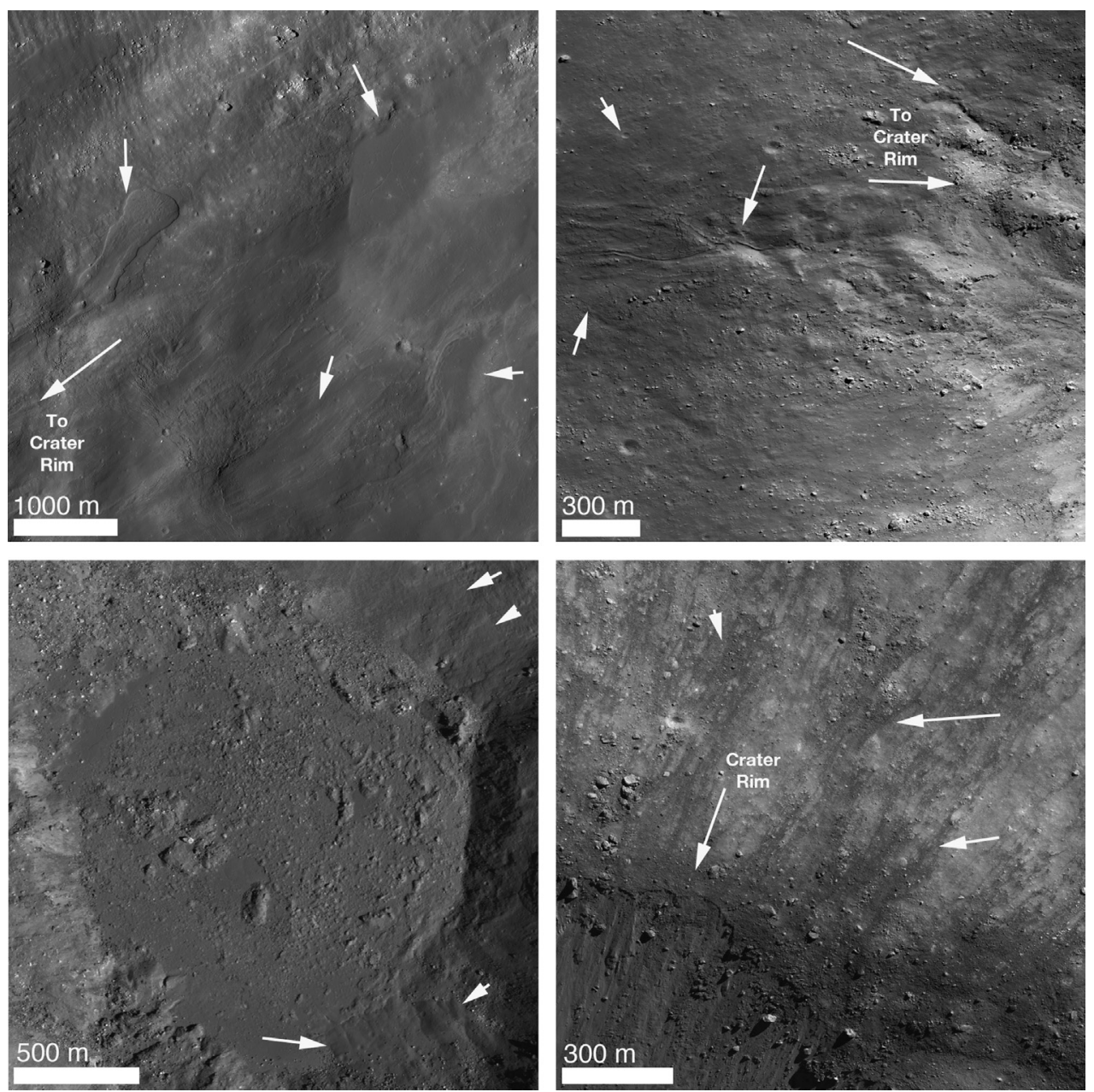

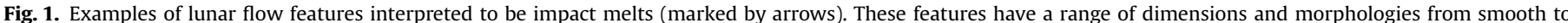

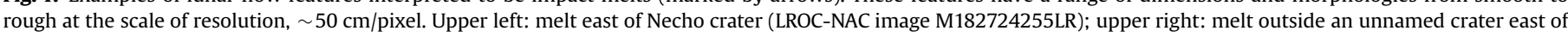

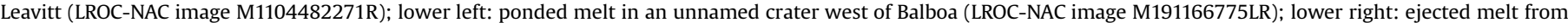
crater Hell Q (LROC-NAC image M12691088LR). Labeled arrows point to crater rims. 
(Fig. 1) typically contain a variety of blocks transported by the partially-molten flow (Dence, 1971; Howard and Wilshire, 1975; Hawke and Head, 1977; Bray et al., 2010).

Given the widespread presence of impact melts on other airless bodies in the solar system, and given the heavily cratered surface of Vesta as revealed by Dawn, one might expect impact melts to occur on Vesta. However, because of the lower impact velocity on asteroids compared to the Moon, Mars and Mercury, previous studies expressed uncertainty whether impact melt deposits could occur on asteroids like Vesta (e.g., Keil et al., 1997). Thus, we conducted a search of Dawn Framing Camera images for lobate, flow-like materials, and we conducted theoretical assessments as to whether and how much impact melt might exist on Vesta.

\section{Results: Observations of vestan lobate features}

We examined Dawn Framing Camera images obtained in the High Altitude Mapping Orbit (HAMO: spatial resolution $\sim 70 \mathrm{~m} /$ pixel) and Low Altitude Mapping Orbit (LAMO: $\sim 20-25 \mathrm{~m} /$ pixel) to examine the variety of lobate, flow-like features on Vesta in order to assess the geologic processes that produced them. We surveyed all latitudes, longitudes, and terrain types that have been illuminated thus far, and here we report on a few examples representative of the variety of lobate features observed on Vesta. We used individual images from the Dawn Framing Camera (Sierks et al., 2011) as well as HAMO and LAMO mosaics produced by the German Aerospace Center (DLR), and we compared recognized lobate features with Survey and HAMO Digital Terrain Models (DTMs) to understand the topographic context of the lobate features.

\subsection{Examples of impact ejecta flow lobes}

Vesta's surface displays many examples of impact ejecta flow lobes (Figs. 2-4). Ejecta from the south polar Rheasilvia basin (center $75^{\circ} \mathrm{S}$, $59^{\circ} \mathrm{E}, \sim 500 \pm 25 \mathrm{~km}$ diameter: Schenk et al., 2012) includes large areas of the continuous ejecta blanket that extend into the equatorial latitudes (Fig. 2), and lobes of discontinuous ejecta that extend into the northern latitudes at least as far as $13^{\circ} \mathrm{N}$ (Fig. 3). The underlying Veneneia basin (center $52^{\circ} \mathrm{S}, 170^{\circ} \mathrm{E}, \sim 400 \pm 25 \mathrm{~km}$ diameter: Schenk et al., 2012) likely also produced far-reaching ejecta, but it is unclear whether Veneneia and Rheasilvia ejecta can be separately distinguished. Smaller, younger craters display a wide variety of lobate ejecta deposits: craters Marcia $(\sim 60 \mathrm{~km})$, Calpurnia $(\sim 52 \mathrm{~km})$, and Minucia $(\sim 23 \mathrm{~km})$ centered on $\sim 15^{\circ} \mathrm{N}, 198^{\circ} \mathrm{E}$ are surrounded by a variable field of low-albedo ejecta (Fig. 4a). In particular, there is a low albedo lobate unit east of Marcia that stands out from the surrounding parts of the ejecta field, and is quite distinctive in the FC Clear filter $(450-920 \pm 10 \mathrm{~nm})$ and Clementine-type color ratio images (Fig. 4b). It consists of variable brighter and darker, smoother and rougher outcrops that appear to be a mixture of various impact-produced material. We interpret this as some combination of impact ejecta and darker material that may or may not be melted, in which the darker material could be derived from carbonaceous chondrite material that dominates this hemisphere of Vesta (Reddy et al., 2012). Above the northern rim of Marcia is a region with variably higher albedo, smoother material (perhaps ponded fine-grained ejecta or impact melt) adjacent to narrow, sinuous flow lobes (Fig. 4c). Within the floor of Marcia (Fig. 4d), Cornelia (Fig. 5), Rheasilvia (Fig. 6a and b), and several other craters, are distinct lobate, flow-like materials. Additionally, within the field of smoother lobate material north of Marcia (Fig. 4e) is a region of pitted terrain that resemble similar materials found on the floors of several vestan craters and also found on Mars (Boyce et al., 2012; Tornabene et al., 2012). Denevi et al. (2012) suggested that these pitted terrains represent release of volatiles from either impactor or target materials, and if so suggest that there may

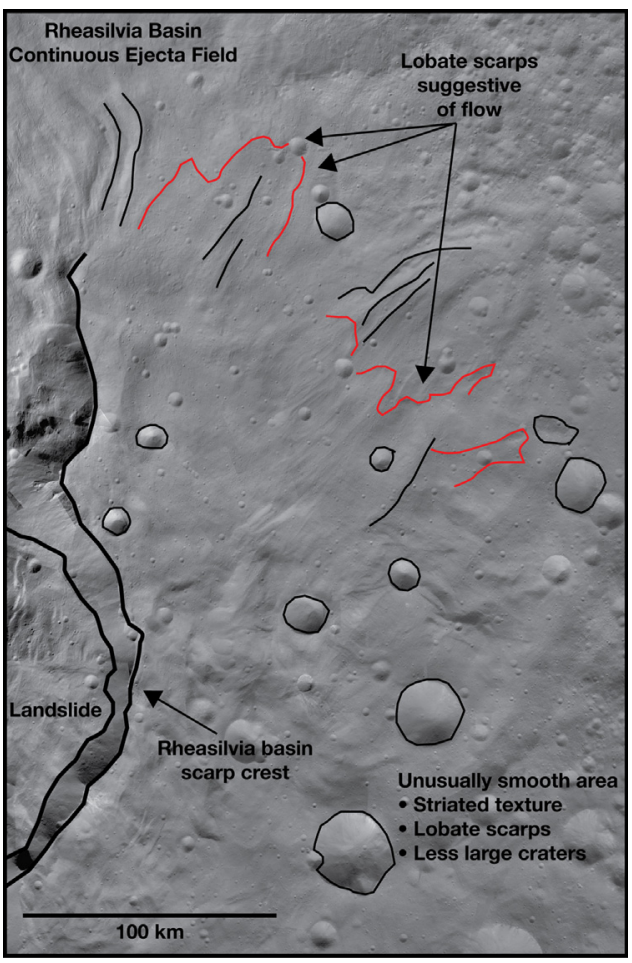

Fig. 2. Part of the continuous impact ejecta blanket of the 505-km diameter Rheasilvia impact basin at the south pole of Vesta, where lobate ejecta has erased large diameter craters. Although not globally visible, this section of the Rheasilvia ejecta field extends at least up to Vesta's equatorial latitudes. Black lines and circles represent scarps and crater rims, respectively. Figure extracted from LAMO mosaic (20 m/pixel), produced by German Aerospace Center (DLR).

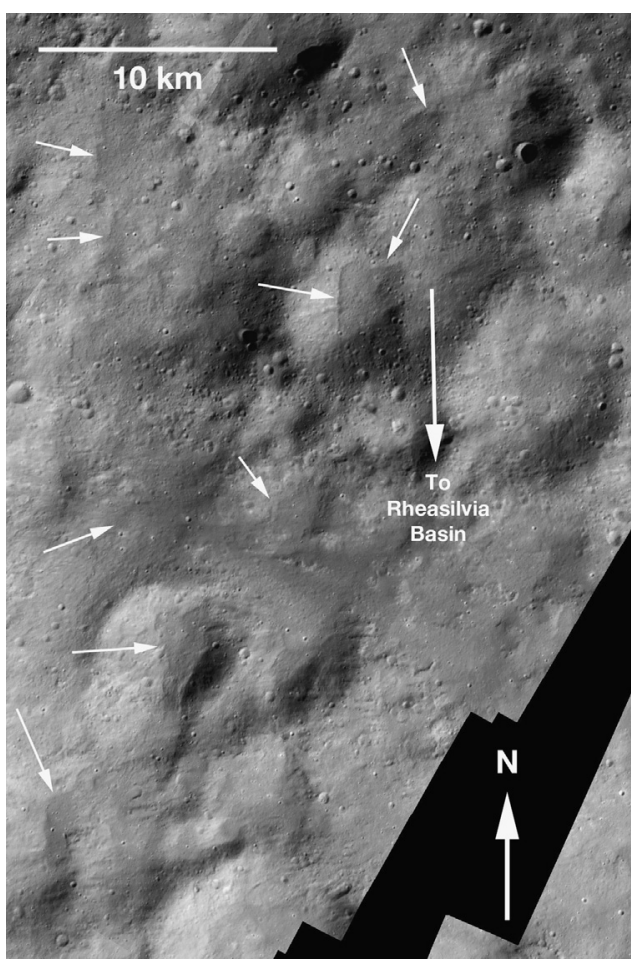

Fig. 3. Lobate material (white arrows) oriented radially to the rim of the Rheasilvia basin, located in Vesta's northern latitudes at $13^{\circ} \mathrm{N}, 168^{\circ} \mathrm{E}$. These features are subtle, having slightly lower albedo and smoother surfaces than the surrounding terrain. This material is inferred to be part of Rheasilvia's discontinuous ejecta blanket. Figure extracted from LAMO mosaic ( $20 \mathrm{~m} /$ pixel), produced by German Aerospace Center (DLR). 
a

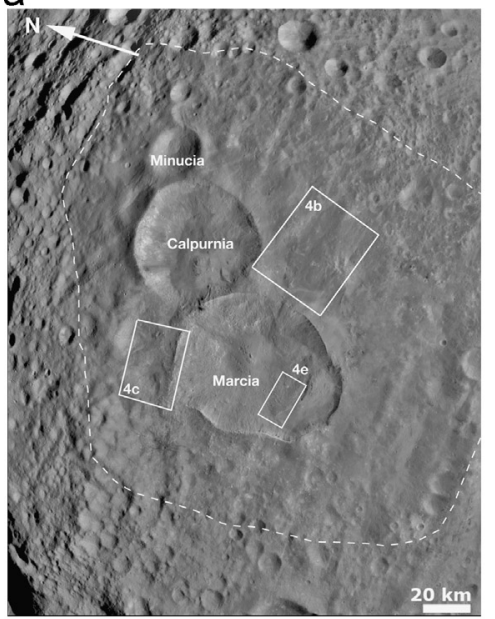

C
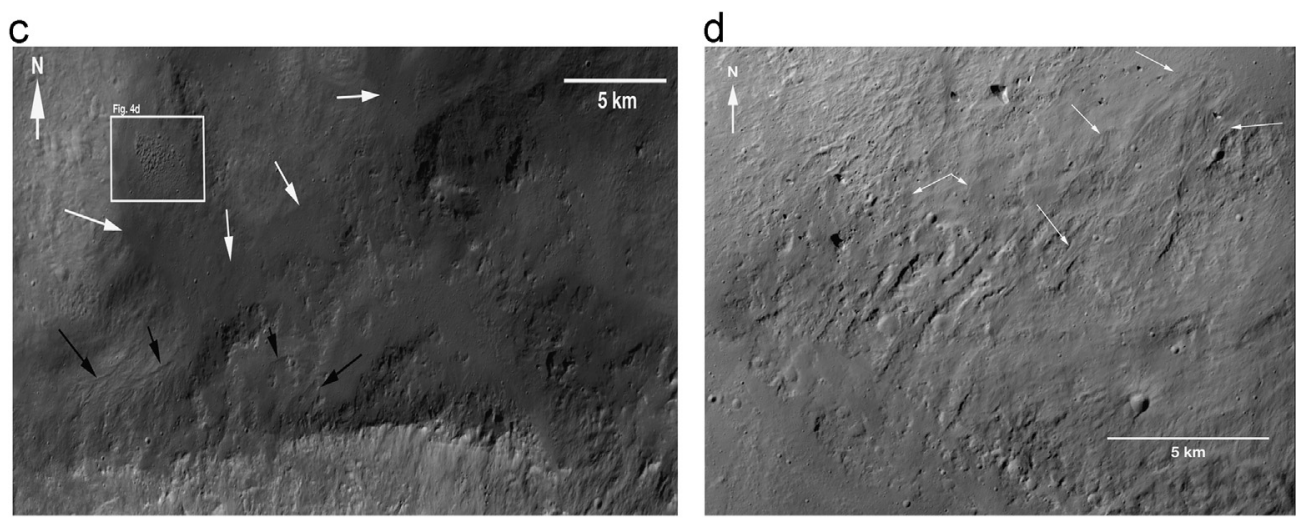

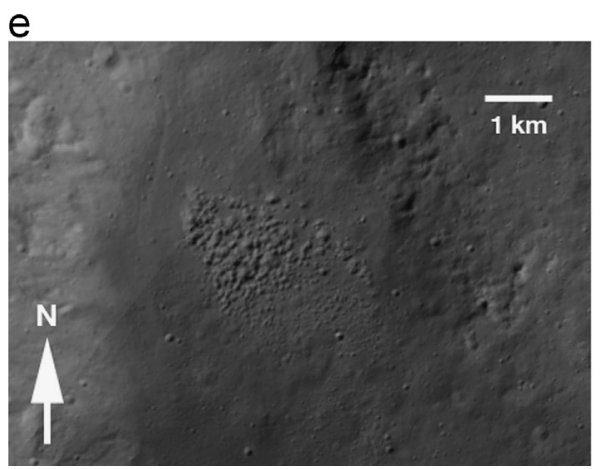

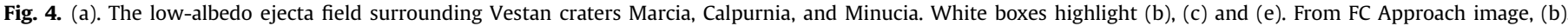

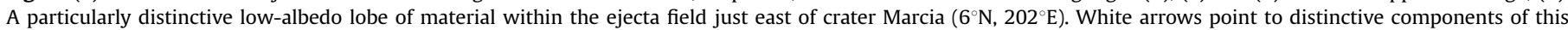

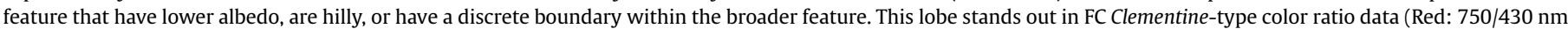

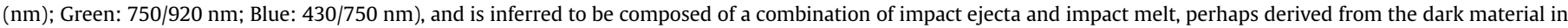

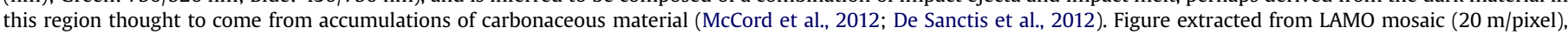

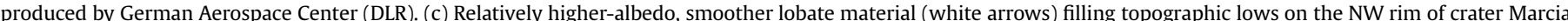

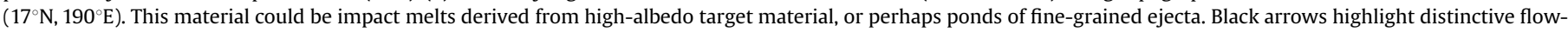

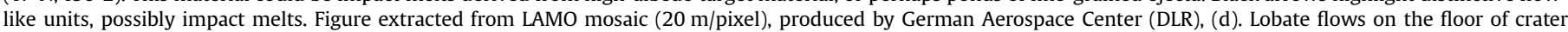

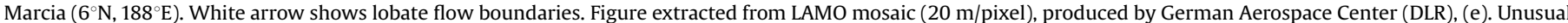

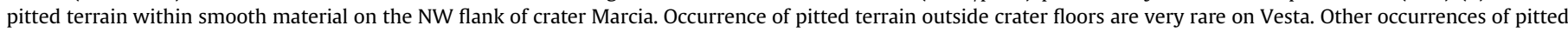

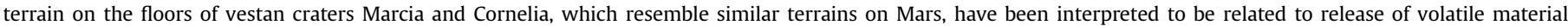

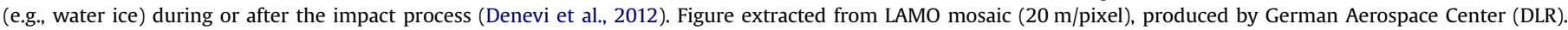
(For interpretation of the references to color in this figure legend, the reader is referred to the web version of this article.)

have been a variable volatile component within some of Vesta's lobate units.

\subsection{The case for impact melts}

Although it is clear that most of Vesta's lobate, flow-like features are impact-related, the evidence for whether they are impact melts as opposed to ejecta flows or a combination of flows and melts is much more ambiguous. Fig. 4c and Fig. 6 show some of Vesta's best examples of putative impact melts. Lobate, flow-like features in Marcia crater (Williams et al., in review) range from tens of meters to $\sim 10 \mathrm{~km}$ long, and those in the Rheasilvia basin can be up to $\sim 25 \mathrm{~km}$ long. These features are generally shorter in length, in contrast to many lunar impact melt flows that occur outside crater rims with lengths of up to several crater radii (e.g., Hawke and Head, 1977). Within the Marcia quadrangle, some of 
the low-albedo lobate material may be a mixture of impact ejecta and impact melt. In contrast, there are also several deposits of higher-albedo smooth material occupying topographic lows, suggestive of either melt materials accumulations of fine-grained fragmental material. It is unclear how thick these units might be; however, assuming a range of thicknesses between 1 and $10 \mathrm{~m}$ and multiplying by the mapped areal extents of these smooth materials (interpreted to be likely impact melt deposits) in and around Marcia and Calpurnia craters $\left(\sim 423 \mathrm{~km}^{2}\right)$, we can estimate impact melt volumes $\sim 0.4-4 \mathrm{~km}^{3}$. If the areal extents of pitted terrain within Marcia and Calpurnia $\left(\sim 552 \mathrm{~km}^{2}\right)$ and bright lobate materials $\left(\sim 122 \mathrm{~km}^{2}\right)$ close to the Marcia rim are included, then the estimated volume of potential impact melt deposits increases to $\sim 11 \mathrm{~km}^{3}$. Are these impact melt volumes reasonable for a low gravity body like Vesta? Later we will turn to theoretical models to investigate how much impact melt might be expected from impacts on Vesta.

\subsection{Lobate features from gravity driven mass movements}

In contrast to lobate features related to impact processes, Dawn Framing Camera images also show several clear examples of landslides, slumps, or other features interpreted to represent

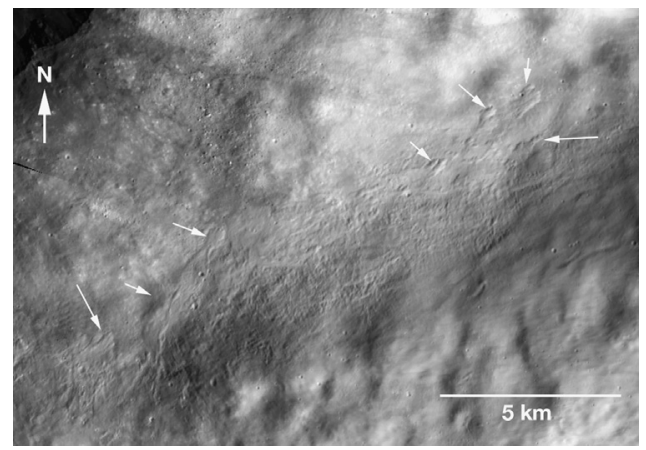

Fig. 5. Narrow, lobate flows in the ejecta field of Cornelia crater $\left(11^{\circ} \mathrm{N}, 229^{\circ} \mathrm{E}\right)$. White arrow shows lobate flow boundaries. Figure extracted from LAMO mosaic (20 m/pixel), produced by German Aerospace Center (DLR).

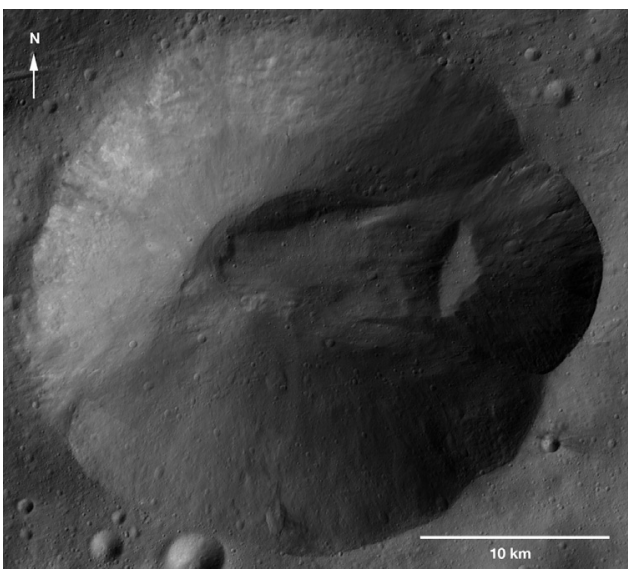

Fig. 7. Lobate flow unit that has moved down the interior slope of crater Octavia $\left(2^{\circ} \mathrm{S}, 148^{\circ} \mathrm{E}\right)$. The morphology of this feature is consistent with gravitationallydriven mass movements, most likely a rotational landslide. Figure extracted from LAMO mosaic ( $20 \mathrm{~m} /$ pixel), produced by German Aerospace Center (DLR).

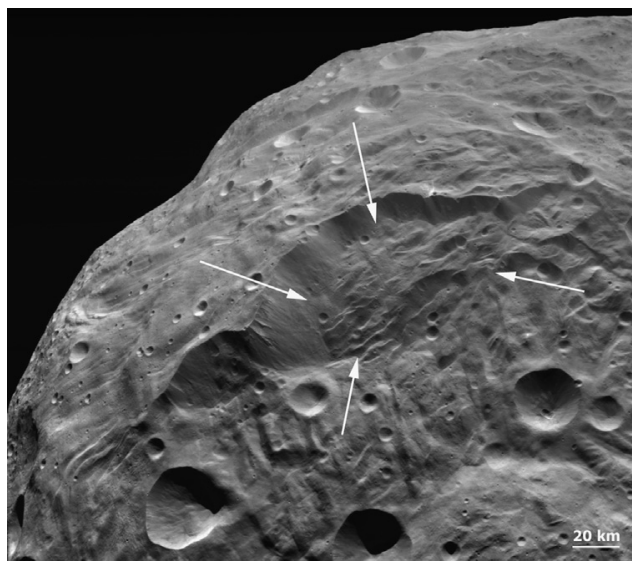

Fig. 8. Rotational landslide deposit inside main scarp of the Rheasilvia basin, located at $54^{\circ} \mathrm{S}, 93^{\circ}$ E. From FC Approach image. a

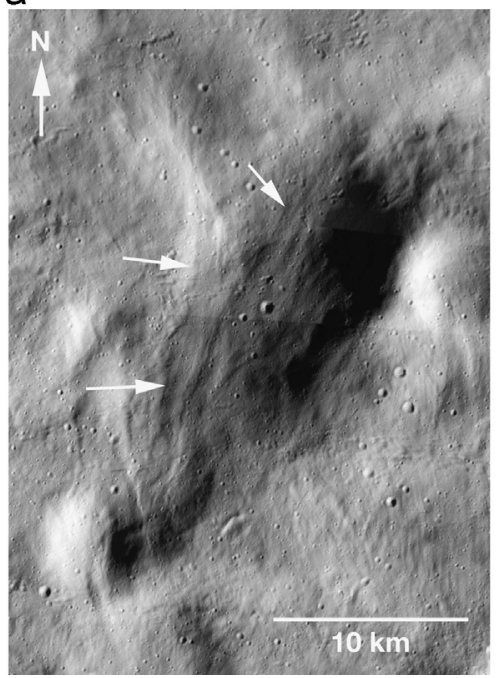

b

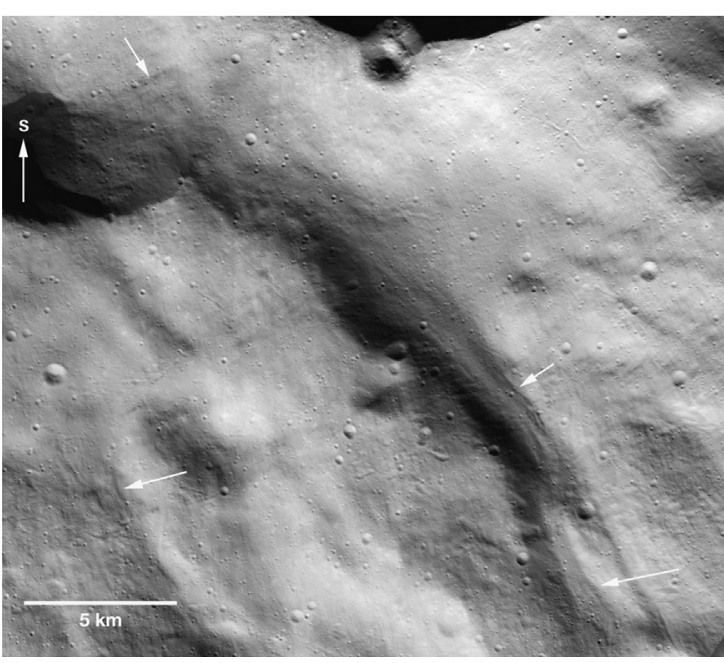

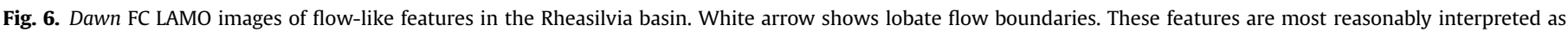

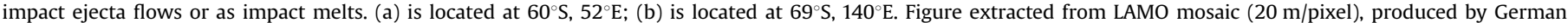
Aerospace Center (DLR). 


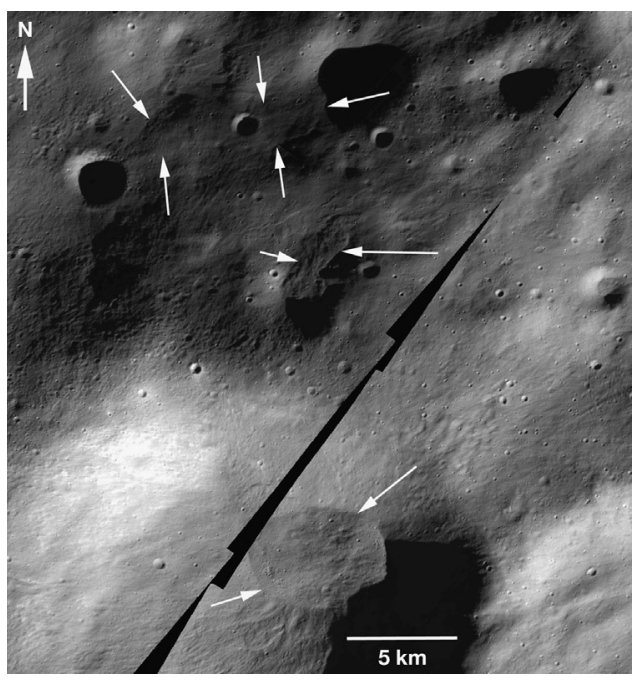

Fig. 9. Flows in and near crater Minucia, highlighted by white arrows. An ovoid deposit (bottom of figure) occurs on the floor of Minucia $\left(21^{\circ} \mathrm{N}, 209^{\circ} \mathrm{E}\right)$, which could be an accumulation of debris transported downslope by mass movement, or alternatively could represent an impact melt deposit. Two smaller lobate flows (top of figure) appear to be related to craters or other depressions, likely either impact ejecta or impact melts. Figure extracted from LAMO mosaic $(20 \mathrm{~m} /$ pixel), produced by German Aerospace Center (DLR).

deposits produced from gravity-driven mass movements. Vesta's ratio of observed relief to size (15\%) is greater than that for the terrestrial planets ( $\sim 1 \%$ : Jaumann et al., 2012), such that impact craters forming on Vesta have a greater likelihood of forming on steeper slopes, resulting in the formation of 'asymmetric craters'. Asymmetric craters (Krohn et al., this issue) have sharp rims on upslope sides of the craters, and subdued rims on the downslope sides of the craters due to the downslope movement of loose material from crater walls. Other craters contain discrete lobate units that resemble terrestrial mass movement deposits. For example, crater Octavia $\left(3^{\circ} \mathrm{S}, 148^{\circ} \mathrm{E}\right)$ contains a well-defined rotational slide deposit (Fig. 7). The well-defined interior scarp of the Rheasilvia basin at $54^{\circ} \mathrm{S}, 93^{\circ} \mathrm{E}$ contains a large rotational slide deposit on its interior flank (Fig. 8). Crater Minucia contains an ovoid deposit on its floor (Fig. 9), which could represent an accumulation of downslope material or impact melt. North of Minucia within the broader Marcia ejecta field are several darker lobate features that appear to originate from small craters. It is unclear whether these are small impact melt flows originating from these craters, or more likely are distal ejecta from Marcia or perhaps the Rheasilvia basin. A more detailed study of mass wasting features in the Rheasilvia basin is presented by Otto et al. (2013).

Hyperspectral data from Dawn's Visible and Infrared Spectrometer (VIR, De Sanctis et al., 2011, 2012) provide additional information on some of Vesta's largest lobate flow-like units. Whereas most of the lobate materials observed in FC images are too small to derive meaningful compositional information, there are a few larger units that can be characterized, as outlined here. For example, a large mass movement is located on the inside scarp of the Rheasilvia basin at $53^{\circ} 25^{\prime} \mathrm{S}, 67^{\circ} 45^{\prime} \mathrm{E}$ (Fig. 10a). This feature has a different composition relative to its surroundings, as shown by the larger Band II depth and by the VIR-derived, Clementinetype color ratio map (Red: $750 / 430 \mathrm{~nm}$, Green: $750 / 920 \mathrm{~nm}$, Blue: $430 / 750 \mathrm{~nm}$, where the feature appears green: Fig. 10b and c). Band I Center and Band II Center that are indicative of the pyroxene composition and enable definition of the eucritic, howarditic or diogenitic components, are located at shorter wavelengths, thus revealing a diogenitic composition (Fig. 10d). Because the incidence and emission angles are as high as $70-80^{\circ}$ for this VIR observation, it is possible that photometric effects could influence the interpreted band depth behaviors for this feature. Nevertheless, the location and composition of this feature are consistent with other studies using VIR data that suggest a more diogenitic composition for materials exposed within wide regions of the Rheasilvia basin (De Sanctis et al., 2012; McSween et al., 2013; McSween et al., in press), suggesting that this mass movement was derived from the remobilization of deeper lower crustal or upper mantle material.

A second region of spectral contrast within Rheasilvia occurs at $-54^{\circ}, 93^{\circ} \mathrm{E}$ (Fig. $11 \mathrm{a}$ ), where a higher-albedo mass movement is superposed on a larger landslide containing distinct blocks suggestive of rotational sliding. This higher-albedo mass movement was observed by VIR during HAMO2. While we did not observe band depth variations, the band centers are located at slightly shorter wavelengths. This suggests a general similar composition between the mass movement and the surroundings, with a different composition of the pyroxene component that seems to be more diogenitic (Fig. 11b and c).

\section{Results II: Modeling impact melts on Vesta}

Dawn FC images clearly show some lobate, flow-like features associated with impact craters that have morphologies consistent with impact melts (Fig. 4c and Fig. 6), although the mappable extents suggest volumes much smaller than lunar impact melt volumes. We now turn to theoretical modeling to assess how much melt should occur from impacts on Vesta. The production of impact melt is highly dependent on impact velocity (e.g., O'Keefe and Ahrens, 1977; Bjorkman and Holsapple, 1987; Pierazzo et al., 1997; Wünnemann et al., 2008). For impacts with a 'melt number' $U^{2} / E_{m}$ greater than $\sim 30$, where $U$ is the impact velocity and $E_{m}$ is the internal energy at the critical shock pressure for melting, the volume of the melted region is significantly larger than the volume of the projectile and the melt volume follows a simple linear relationship in log-log space:

$\log \left(V_{\text {melt }} / V_{\text {imp }}\right)=\mathrm{a}+3 / 2 \mu \log \left(U^{2} / E_{m}\right)$

where $V_{\text {melt }}$ and $V_{i m p}$ are the volume of melt and the volume of the impactor, and $a$ and $\mu$ are constants. For non-porous dunite, Wünnemann et al. (2008) find $a=-0.871, \mu=0.662$, and $E_{m}=6.10 \times$ $10^{6} \mathrm{~J} / \mathrm{kg}$. The mean impact velocity on the Moon is $\sim 17.5 \mathrm{~km} / \mathrm{s}$ (Ivanov and Hartmann, 2007), giving a melt number of $\sim 50$ assuming dunite composition, well within the range where the above equation applies. Vesta has a mean impact velocity with other asteroids of $\sim 4.75 \mathrm{~km} / \mathrm{s}$ (slightly lower than the main-belt average value of $5.14 \mathrm{~km} / \mathrm{s}$ ) with a high-velocity 'tail' such that about $6 \%$ occur at more than $8 \mathrm{~km} / \mathrm{s}$ and about $2 \%$ occur at more than $10 \mathrm{~km} / \mathrm{s}$ (O'Brien and Sykes, 2011). Even these higher velocities, though, are below the range where the above equation applies.

For this range of velocities, we use the results of simulations based on those presented in Davison et al. (2010) for impacts between dunite projectiles and a dunite target, where both are spherical and the target has a radius 10 times larger than the projectile. The projectile and target are both initially at $T_{o}=300 \mathrm{~K}$, following the earlier Davison et al. simulations, and cases are run with the projectile and target both having $0 \%$ porosity and both having $20 \%$ porosity. The porosity of the projectile has relatively little effect on the amount of heating and melt production in the target, which is primarily determined by target porosity. The results of these simulations are shown in Fig. 12, giving the melt volume (scaled to projectile volume) as a function of impact velocity. Vertical impacts are assumed. Two features are immediately apparent. First, the melt production drops off steeply at lower 

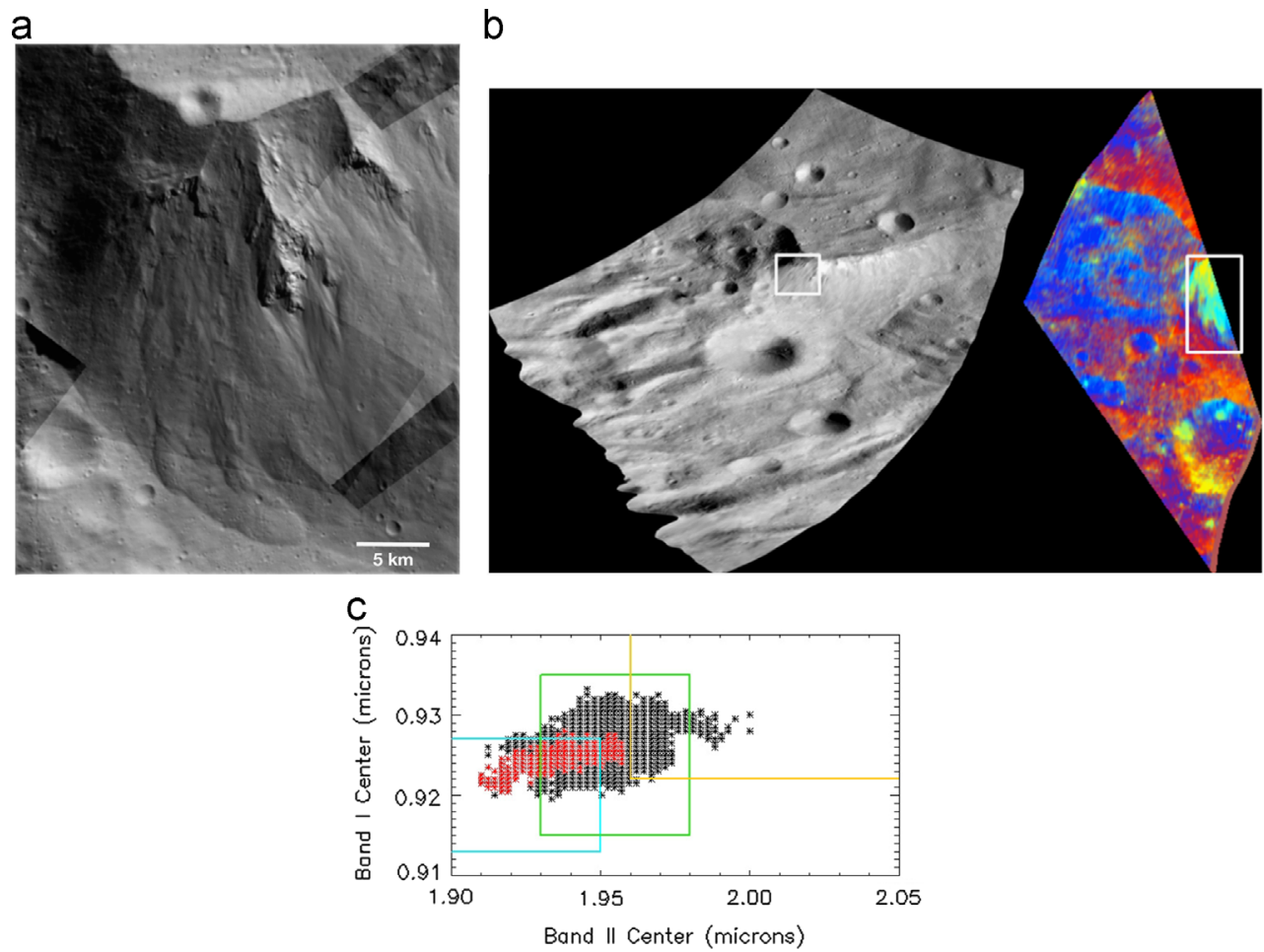

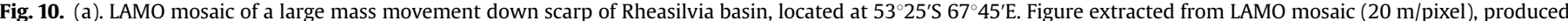

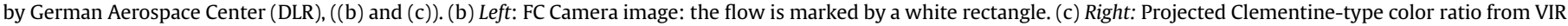

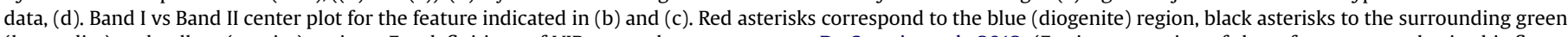

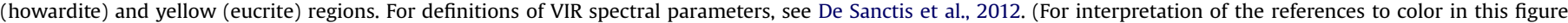
legend, the reader is referred to the web version of this article.)

impact velocities that occur for asteroids. And second, porosity can significantly increase the amount of melt produced, which has also been shown in other work (e.g., Wünnemann et al., 2008). Keil et al. (1997) suggested that melt production should be minimal at asteroidal collision velocities, which is likely true if the material has no porosity. These results show that a modest porosity could allow for greatly increased melting.

To estimate the melt volumes possible for impact craters on Vesta, we start with the scaling law by Schmidt and Housen (1987) parameterized in terms of projectile diameter (e.g., Ivanov, 2001; Ivanov and Hartmann, 2007):

$D_{t c}=1.16(\delta / \rho)^{1 / 3} D_{p}{ }^{0.78} U^{0.44} g^{-0.22}$ (wetsoil, rock)

which gives the transient crater diameter $D_{t c}$ as a function of projectile and target densities $\delta$ and $\rho$, projectile diameter $D_{p}$, vertical impact velocity component $U$, and surface gravity $g$ $\left(0.22 \mathrm{~m} / \mathrm{s}^{2}\right.$ for Vesta, $1.6 \mathrm{~m} / \mathrm{s}^{2}$ for the Moon). This scaling law is for wet soil and rock; other forms have been derived for sand and other materials that may be better analogies for regolith, but this form is most suitable for craters that penetrate several $\mathrm{km}$ or more into the surface, much deeper than the depth of loose regolith as inferred for Vesta.

Eq. (2) assumes that impact craters form in the gravity regime, in which crater size is limited by gravity rather than material strength. The strength to gravity transition diameter scales roughly as $1 / \mathrm{g}$, and is $\sim 400 \mathrm{~m}$ for the Moon (e.g., Melosh, 1989), which scales to $\sim 3 \mathrm{~km}$ on Vesta. Thus, gravity scaling should apply for the craters on Vesta that we consider here, which are all larger than $10 \mathrm{~km}$ diameter. We first convert the observed crater diameter $D_{\text {crat }}$ into the transient crater diameter $D_{t c}$. For large craters on Vesta, which has a simple-to-complex transition $D_{s c}$ of roughly $30 \mathrm{~km}$ (Schenk et al., in preparation), we use the relation: $D_{t c}=D_{\text {crat }}^{0.85} D_{s c}^{0.15} / 1.25,\left(D_{\text {rat }}>D_{s c}\right)$

For comparison, $D_{s c}$ on the Moon is roughly $17.5 \mathrm{~km}$ (e.g., Pike, 1976). This relation takes into account the large-scale deformation as a crater transitions from simple to complex shape (Croft, 1985) as well as an enlargement by a factor of $\sim 1.25$ due to gravitational slumping of the walls of the crater (e.g., Ivanov and Hartmann, 2007). For craters smaller than $D_{s c}$ that retain a simple shape, we only account for the gravitational slumping:

$D_{\text {tc }}=D_{\text {crat }} / 1.25,\left(D_{\text {crat }}<D_{\text {sc }}\right)$

Eq. (2) is then solved to give the projectile diameter $D_{p}$ for a given transient crater size. The melt volume is determined from the projectile diameter and impact velocity using the relations in Fig. 12. From this we can plot the melt volume (as fraction of crater volume) for a range of crater sizes, impact velocities, scaling laws, and porosities, assuming that the transient crater shape is a paraboloid of revolution and $V_{c r a t}=1 / 2 \pi\left(D_{t c} / 2\right)^{2} d=1 / 8 \pi D_{t c}{ }^{3}$ $r_{d D}$, where $r_{d D}=1 / 2.7$ is the depth/diameter ratio for the transient crater (Melosh, 1989) and $d$ is the crater depth.

Results are shown in Fig. 13a-d and in Table 1. The grey region for the Moon is the same in all panels, and assumes an impact velocity of $17.5 \mathrm{~km} / \mathrm{s}$, with the lower bound given by $0 \%$ porosity and the upper bound by $20 \%$ porosity (the latest results from the GRAIL mission place the average lunar crustal porosity at $12 \%$, Wieczorek et al., 2013). Vertical impacts are assumed in all cases. Pierazzo and Melosh (2000) find, from hydrocode modeling of oblique impacts, that the melt volume (as fraction of crater volume) does not simply scale as the vertical component of the impact velocity, as might be expected. Rather, for a given crater 
a

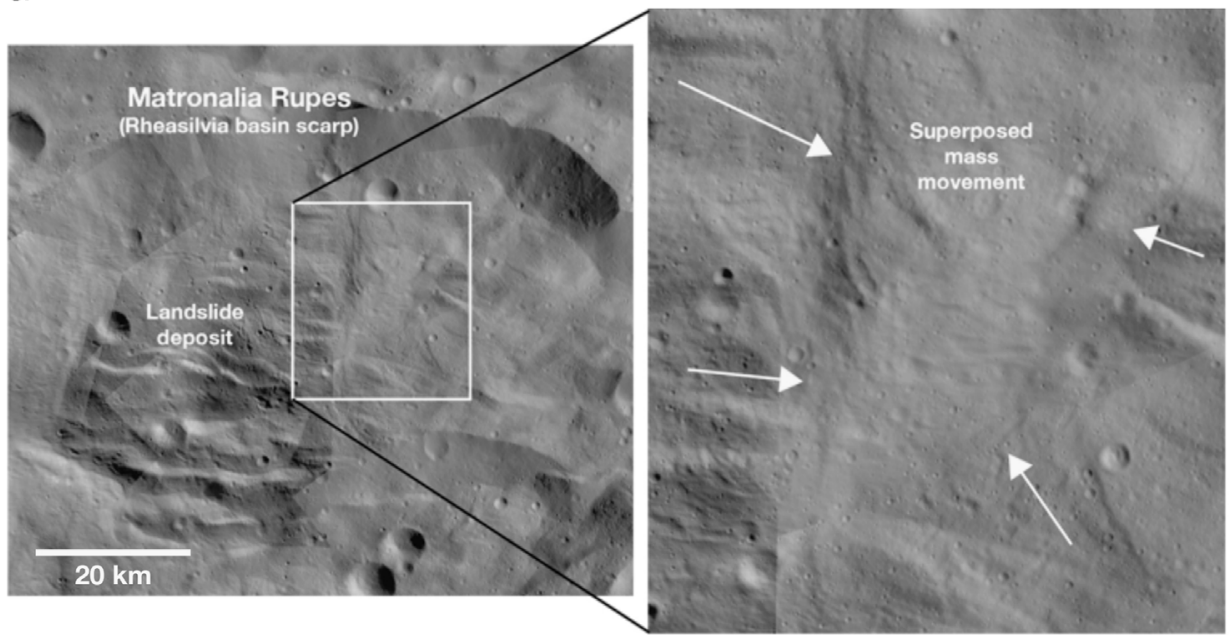

b

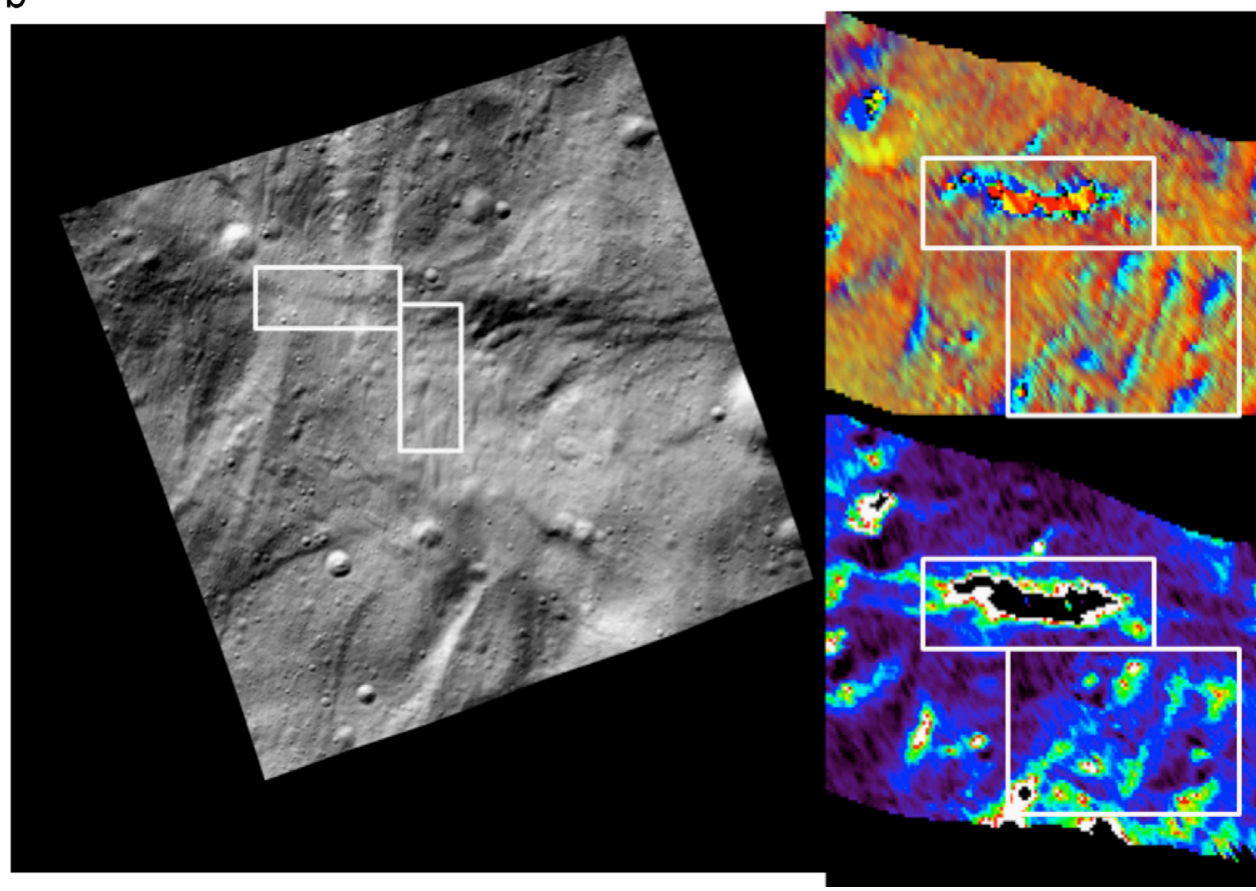

Fig. 11. (a) Dawn FC image of a higher-albedo mass movement superposed on the large landslide within the Rheasilvia basin, (b) and (c). Left: FC camera image (Note: 90 clockwise rotation from the right side of (a). The deposit is enclosed within the white rectangles. Right, top: Projected Clementine ratio from VIR data. Right, bottom: I/F ratio between 2.02 and $1.92 \mu \mathrm{m}$, representing the composition (blue: eucritic, green diogenitic). White boxes highlight diogenitic material. (For interpretation of the references to color in this figure legend, the reader is referred to the web version of this article.)

diameter, melt volume is a roughly constant fraction of the crater volume regardless of the impact angle, so the values for the Moon plotted in Fig. 13a-d are likely to be fairly insensitive to impact angle. Note however that for oblique impacts, a larger fraction of the melt may end up ejected beyond the crater rim, leaving less within the crater itself (e.g., Plescia and Cintala, 2012).

For lower-velocity impacts like those on Vesta, the scaling for melt production in Eq. (1) breaks down and the decrease in melt volume is likely to be more severe as the impact angle deviates from vertical, so the values plotted in Fig. 13a-d for Vesta should be taken as upper limits that will occur for near-vertical impacts, but are not necessarily representative of the average impact angle of $45^{\circ}$. Impacts within 30 degrees from vertical should occur in $25 \%$ of cases (e.g., Gilbert, 1893; Shoemaker, 1962), and for those impacts, the vertical velocity component is within $\sim 10 \%$ of the impact velocity (e.g., a $10 \mathrm{~km} / \mathrm{s}$ impact at $30^{\circ}$ from vertical will have a vertical velocity component of $8.7 \mathrm{~km} / \mathrm{s}$ ). These nearvertical impacts, when they occur at above-average impact velocity, have the best chance of generating significant impact melt on Vesta.

Let's consider as a test case the vestan impact crater Marcia, one of the youngest, freshest large craters on Vesta (Jaumann et al., 2012; Denevi et al., 2012). Assuming for simplicity a crater diameter of $50 \mathrm{~km}$, for vertical impacts with velocities $\sim 5-10 \mathrm{~km} / \mathrm{s}$ and target porosities of $0-20 \%$, our modeling predicts that the Marcia impact event could have produced impact melt volumes ranging from $\sim 0.025 \mathrm{~km}^{3}$ to $32 \mathrm{~km}^{3}$. Most of this material will likely remain in the crater, although some fraction of can be emplaced exterior to the rim (e.g., Osinski et al., 2011). While these volumes are substantially less than for similar-sized 
craters on the Moon (estimated as $65-140 \mathrm{~km}^{3}$ using similar scaling and an impact velocity of $17.5 \mathrm{~km} / \mathrm{s}$ ), these model results are consistent with the estimates of melt volumes from mapping putative melt features around Marcia crater $\left(\sim 0.4-11 \mathrm{~km}^{3}\right)$. Thus, both image analyses and modeling calculations suggest that there should be some relatively small deposits of impact melts

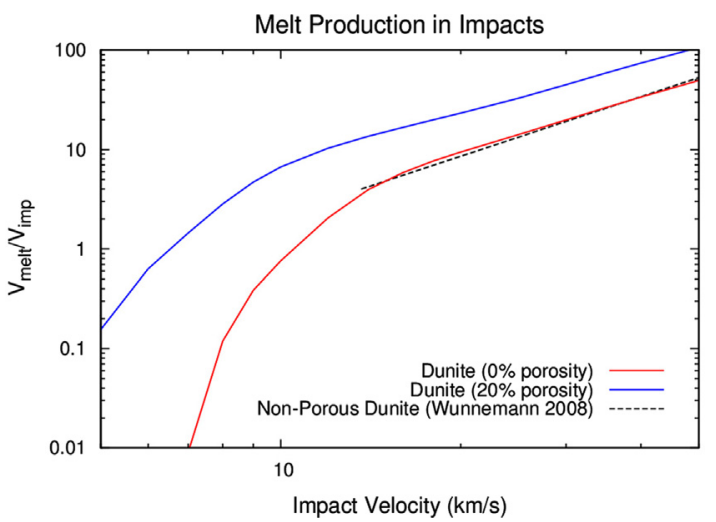

Fig. 12. Results of simulations based on those presented in Davison et al. (2010 2013) for impacts between dunite projectiles and a dunite surface (both initially at $T_{o}=300 \mathrm{~K}$ ) with porosities of $0 \%$ and $20 \%$. Melt volume (scaled to projectile volume) as a function of impact velocity is plotted for two different porosities, along with a best-fit line for dunite from the simulations of Wünnemann et al. (2008) for melt number $U^{2} / E_{m}$ greater than $\sim 30$. Vertical impacts are assumed here, giving an upper-limit estimate for the melt production.

associated with some large craters on Vesta, especially those

a

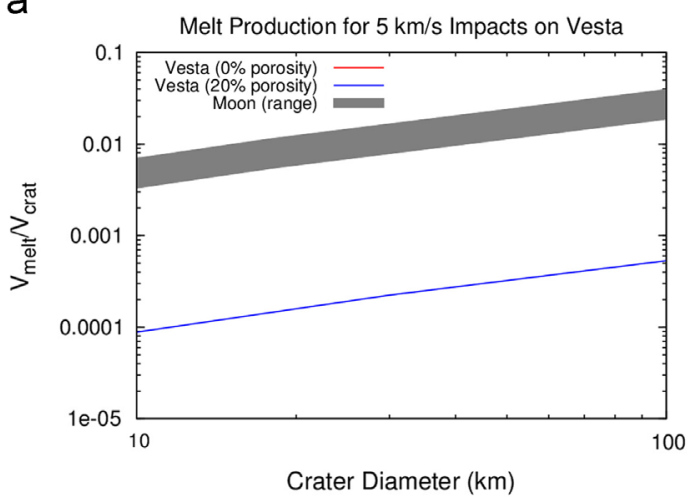

C

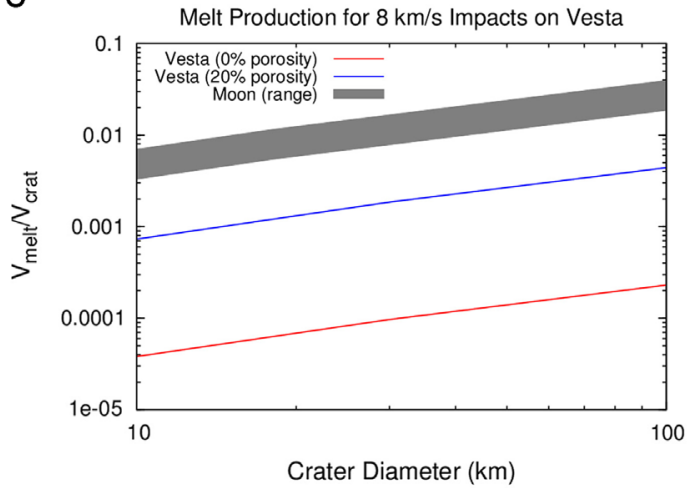

Table 1

Model results estimating volumes of impact melt produced for targets of $0 \%$ and $20 \%$ porosity for specific impactor sizes. Refer to Fig. 13a-d.

\begin{tabular}{llllll}
\hline $\begin{array}{l}D_{\text {crat }} \\
(\mathrm{km})\end{array}$ & $\begin{array}{l}U \\
(\mathrm{~km} / \mathrm{s})\end{array}$ & $\begin{array}{l}V_{\text {melt }} / V_{\text {crat }}: \\
0 \% \text { porosity }\end{array}$ & $\begin{array}{l}V_{\text {melt }} / V_{\text {crat }}: \\
20 \% \text { porosity }\end{array}$ & $\begin{array}{l}V_{\text {melt }}\left(\mathrm{km}^{3}\right) \\
0 \% \text { porosity }\end{array}$ & $\begin{array}{l}V_{\text {melt }}\left(\mathrm{km}^{3}\right) \\
20 \% \text { porosity }\end{array}$ \\
\hline 500 & 5 & $1.8 \times 10^{-5}$ & $1.7 \times 10^{-3}$ & $4.7 \times 10^{1}$ & $4.4 \times 10^{3}$ \\
500 & 6 & $2.2 \times 10^{-5}$ & $5.1 \times 10^{-3}$ & $5.7 \times 10^{1}$ & $1.3 \times 10^{4}$ \\
500 & 8 & $7.3 \times 10^{-4}$ & $1.4 \times 10^{-2}$ & $1.9 \times 10^{3}$ & $3.7 \times 10^{4}$ \\
500 & 10 & $3.2 \times 10^{-3}$ & $2.3 \times 10^{-2}$ & $8.4 \times 10^{3}$ & $5.9 \times 10^{4}$ \\
50 & 5 & $3.4 \times 10^{-6}$ & $3.2 \times 10^{-4}$ & $2.5 \times 10^{-2}$ & $2.4 \times 10^{0}$ \\
50 & 6 & $4.1 \times 10^{-6}$ & $9.7 \times 10^{-4}$ & $3.0 \times 10^{-2}$ & $7.2 \times 10^{0}$ \\
50 & 8 & $1.4 \times 10^{-4}$ & $2.7 \times 10^{-3}$ & $1.0 \times 10^{0}$ & $2.0 \times 10^{1}$ \\
50 & 10 & $6.1 \times 10^{-4}$ & $4.3 \times 10^{-3}$ & $4.5 \times 10^{0}$ & $3.2 \times 10^{1}$ \\
35 & 5 & $2.7 \times 10^{-6}$ & $2.5 \times 10^{-4}$ & $7.9 \times 10^{-3}$ & $7.4 \times 10^{-1}$ \\
35 & 6 & $3.2 \times 10^{-6}$ & $7.5 \times 10^{-4}$ & $9.5 \times 10^{-3}$ & $2.2 \times 10^{0}$ \\
35 & 8 & $1.1 \times 10^{-4}$ & $2.1 \times 10^{-3}$ & $3.2 \times 10^{-1}$ & $6.2 \times 10^{0}$ \\
35 & 10 & $4.8 \times 10^{-4}$ & $3.3 \times 10^{-3}$ & $1.4 \times 10^{0}$ & $1.0 \times 10^{1}$ \\
20 & 5 & $1.7 \times 10^{-6}$ & $1.6 \times 10^{-4}$ & $1.0 \times 10^{-3}$ & $9.5 \times 10^{-2}$ \\
20 & 6 & $2.0 \times 10^{-6}$ & $4.8 \times 10^{-4}$ & $1.2 \times 10^{-3}$ & $2.8 \times 10^{-1}$ \\
20 & 8 & $6.9 \times 10^{-5}$ & $1.3 \times 10^{-3}$ & $4.1 \times 10^{-2}$ & $7.8 \times 10^{-1}$ \\
20 & 10 & $3.0 \times 10^{-4}$ & $2.1 \times 10^{-3}$ & $1.8 \times 10^{-1}$ & $1.3 \times 10^{0}$ \\
10 & 5 & $9.4 \times 10^{-7}$ & $8.8 \times 10^{-5}$ & $7.0 \times 10^{-5}$ & $6.6 \times 10^{-3}$ \\
10 & 6 & $1.1 \times 10^{-6}$ & $2.6 \times 10^{-4}$ & $8.4 \times 10^{-5}$ & $2.0 \times 10^{-2}$ \\
10 & 8 & $3.8 \times 10^{-5}$ & $7.3 \times 10^{-4}$ & $2.8 \times 10^{-3}$ & $5.4 \times 10^{-2}$ \\
10 & 10 & $1.7 \times 10^{-4}$ & $1.2 \times 10^{-3}$ & $1.3 \times 10^{-2}$ & $8.8 \times 10^{-2}$ \\
& & & & & \\
& & & & &
\end{tabular}

Note: $D_{\text {crat }}$ is the crater diameter, $U$ is the vertical impact velocity, columns 3 and 4 give the melt volume as a fraction of the final crater volume $\left(V_{\text {melt }} / V_{\text {crat }}\right)$ for two different porosity values, and columns 5 and 6 give the total melt volume ( $V_{\text {melt }}$ ).

b

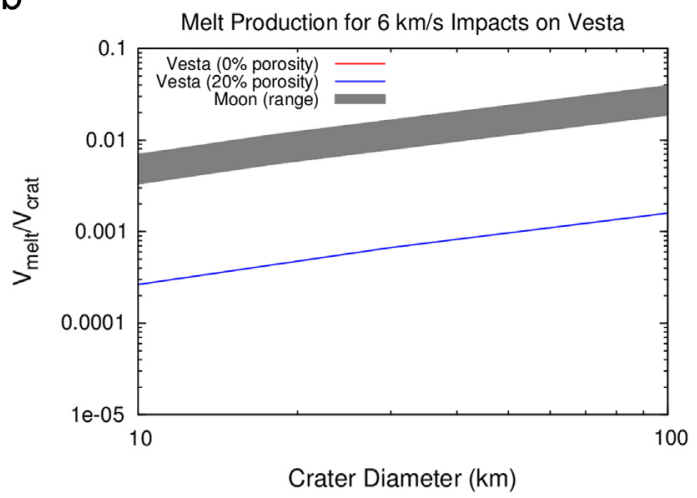

d

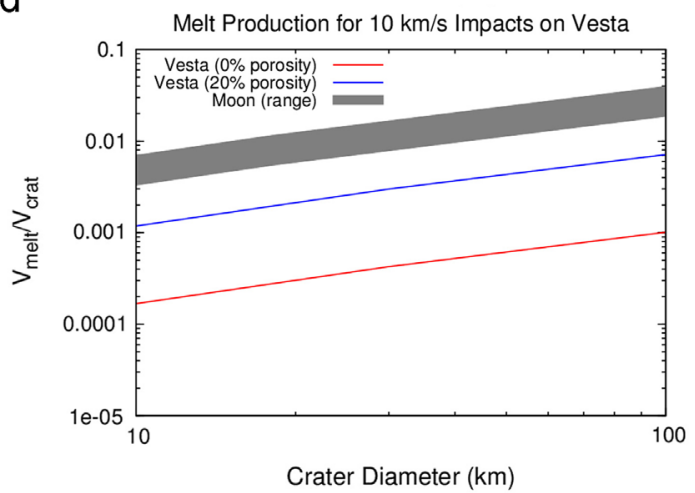

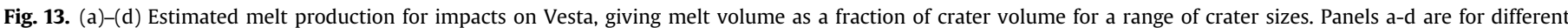

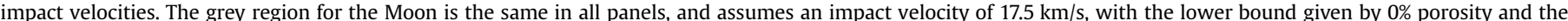

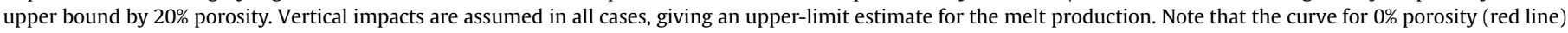

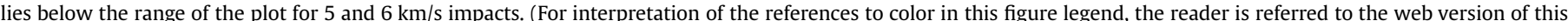
article.) 
forming at above-average impact velocity.

\section{Discussion}

\subsection{Volcanic hypothesis}

The assumption of volcanic materials on Vesta's surface was well justified prior to the Dawn mission. Earth-based telescopic observations showed spectral evidence of basaltic mineralogies, and the inferred relationship of the HED meteorites to Vesta is well established (e.g., McCord et al., 1970; Feierberg et al., 1980; Gaffey, 1997; Binzel et al., 1997; Cochran and Villas, 1998) and has been confirmed by the Dawn observations (Russell et al., 2012; De Sanctis et al., 2012). Petrologic study of the Vesta-derived HED meteorites demonstrates the presence of basaltic minerals and glassy textures that are diagnostic of basaltic lava flows on Earth (McSween et al., 2011, 2013), or alternatively that these basaltic minerals were derived from crystallization of a global magma ocean that may have once covered Vesta (e.g., Righter and Drake, 1997; Ruzicka et al., 1997; Warren, 1997). Given the strong likelihood of basaltic volcanism on Vesta inferred from telescopic data and the HED connection, Wilson and Keil $(1996,1997)$ used mathematic and petrologic models to predict the types of volcanic deposits that should occur on Vesta, including: (a) surface basaltic lava flows with widths of a few hundred meters to a few kilometers, lengths between a few kilometers to several tens of kilometers, thicknesses between 5 and $20 \mathrm{~m}$, and erupted volumes $<3 \mathrm{~km}^{3}$; (b) formation of channelized flows on steeper slopes; (c) a lack of uniform sheet flows; d) a lack of shield volcanoes; (e) shallow intrusions (dikes) with widths of $\sim 1 \mathrm{~m}$ and vertical extents of $<10 \mathrm{~km}$, (f) deep intrusions (dikes) with thicknesses $\leq 3 \mathrm{~m}$ and lateral extents $\leq 30 \mathrm{~km}$, and volumes between 3 and $10,000 \mathrm{~km}^{3}$; and ( $\mathrm{g}$ ) explosive eruptions only occurring in the form of optically-dense lava fountains that form lava ponds feeding lava flows, such that no broad pyroclastic fall deposits should occur on Vesta. A recent reappraisal of their prior work (Keil and Wilson, 2012) continues to support their earlier modeling results regarding sizes of lava flows and pyroclastic deposits on Vesta. Thus, given these studies, we expected prior to Vesta arrival that some volcanic features, particularly lobate lava flows, would be present on the surface, although they would probably have been heavily disrupted by impact craters and thus not easily recognized. Indeed, volcanism on Vesta is thought to have ceased early in Vesta's history, perhaps within $\sim 10-100$ Ma after formation (e.g., Schiller et al., 2010; McSween et al., 2011).

After analysis of HAMO and LAMO images covering $~ 85 \%$ of Vesta's surface, we find no unequivocal morphological evidence for volcanic-related flow features on the surface of Vesta. The widespread distribution of impact craters and impact ejecta testifies to the dominant influence of impact processes in gardening Vesta's surface, such that any large-scale (tens of meters in size or larger) evidence of Vesta's ancient volcanism is likely to have been destroyed. Alternatively, if the volcanism on Vesta manifested itself only as a global magma ocean, which cooled and crystallized to form basaltic minerals in widespread flow fields as opposed to discrete individual flows (similar to the larger basinfilling lunar maria), then this might also explain the lack of observed volcanic flow features. In either case, the lack of discrete volcanic features on Vesta is consistent with the hypothesis, based on analysis of basaltic material in the HED suite, that volcanism on Vesta occurred only during the first $\sim 10-100$ Ma of Vesta's history (e.g., Schiller et al., 2010; McSween et al., 2011), and that since then impact processes have degraded any ancient volcanic features to the point where they cannot be distinguished. It is possible that ongoing detailed study of Vesta's surface as part of the quadrangle mapping process may yet identify some small battered fragments of ancient volcanic features; perhaps the best place to investigate is Vestalia Terra, which appears to be a continent-sized fragment of Vesta's original crust (Buczkowski et al., 2013), albeit disrupted and blanketed by superposed impact ejecta.

\subsection{Impact and erosional sources for lobate features}

All lobate flow-like features on Vesta occur either in proximity to impact craters, or on steep slopes, suggesting that either impact or erosional processes are responsible for the formation of these features. The majority of these features are directly traceable to impact craters as their sources, and are morphologically similar to impact ejecta deposits observed on other airless bodies. Thus we interpret most of Vesta's impact-related lobate features to be flows of impact ejecta. However, a few of the more distinctive flow-like features with smoother surfaces at LAMO resolution are suggestive of impact melts. We reiterate that our modeling suggests that the best chance for melt production on Vesta is from impacts with above-average velocity that are close to vertical, so that impact melt production should happen but not be commonplace: 8-10 km/s impacts are uncommon but not impossible on Vesta, with $6 \%$ of all impacts occurring at $8 \mathrm{~km} / \mathrm{s}$ and $2 \%$ at $10 \mathrm{~km} / \mathrm{s}$, and impacts within 30 degrees of vertical should occur in $25 \%$ of cases (e.g., Gilbert, 1893; Shoemaker, 1962). This is consistent with the relatively small number of features we find on Vesta that we interpret as impact melt, and the relatively small volumes measured of this putative melt material $\left(\sim 0.4-11 \mathrm{~km}^{3}\right)$. Furthermore, the HED meteorites contain very little impact melts, further suggesting that they are likely not produced in large amounts on Vesta. Alternatively, if the smooth materials are simply accumulations of fine-grained materials rather than impact melts (which were ejected from the crater interior), then the volume of impact melt estimated from study of Dawn images would be closer to the lower end of our modeling predictions. Nevertheless, features visible in Dawn FC images that could be interpreted as impact melt deposits are consistent with our model predictions for a very limited volumetric range of impact melts based on our understanding of impact processes on Vesta.

\section{Conclusions}

We studied images from the Dawn mission's HAMO and LAMO orbits, covering $\sim 85 \%$ of Vesta, to assess the geologic processes that likely formed lobate, flow-like features on the surface. There is no unequivocal morphologic evidence of ancient volcanic features preserved on Vesta, likely because of the early cessation of volcanism within $\sim 10-100$ Ma after formation (e.g., Schiller et al., 2010; McSween et al., 2011) and the subsequent bombardment by impactors at all size ranges. We find that all lobate, flowlike materials are located close to impact craters or on steep slopes, indicating a likely formation as a result of impact and erosional processes. Impact ejecta lobes are prominent radial to many impact craters, and are the source for many of the lobate features. A small subset of distinctive flow-like features, some with smooth upper surfaces and a variety of albedos, interpreted as impact melts, are found in and around several of the larger craters and basins. Volumes of these putative melts from Dawn image analysis are consistent with results from theoretical estimates of melt production, suggesting relatively small amounts of impact melt (tens of millions of cubic meters to a few tens of cubic kilometers) could be produced by the Marcia-sized ( $D \sim 60 \mathrm{~km})$ impacts on Vesta (especially in the case of near-vertical impacts with above-average velocity), although the volumes are far less 
than on larger gravity bodies such as the Moon that have significantly larger average impact velocities. Other lobate deposits appear to be associated with gravity-driven mass movements, include rotational landslides, slumps, and talus accumulations in topographic lows. These deposits are consistent with the prevalence of steep slopes identified from stereo image analysis (Jaumann et al., 2012) of Vesta's surface.

\section{Acknowledgments}

We thank Catherine Neish and Matteo Massironi for very helpful reviews that improved the quality of this paper. We would like to thank the Dawn Flight Team for their tireless work operating the spacecraft and returning the data used in this study. We also thank the Framing Camera teams at the Max Planck Institute (KatlenbergLindau) and the German Aerospace Center (DLR) and the VIR team at the National Institute of Astrophysics (Rome) for their work process the Dawn data. This work was funded by NASA through the Discovery Program and Dawn Project Office at the Jet Propulsion Laboratory, and by the NASA Dawn at Vesta Participating Scientists Program through grant NNX10AR24G to DAW and grant NNX10AR21G to DPO.

\section{References}

Barlow, N.G., A review of Martian impact crater ejecta structures and their implications for target properties, In:: Kenkmann, T., Hörz, F., Deutsch, A. (Eds.), Large Meteorite Impacts III, Geological Society of America Special Pape 384 Geological Society of America, Boulder, CO, 433-442, 2005.

Binzel, R.P., Gaffey, M.J., Thomas, P.C., Zellner, B.H., Storrs, A.D., Wells, E.N., 1997 Geologic mapping of Vesta from 1994 Hubble Space Telescope images. Icarus 128, 95-103.

Bjorkman, M.D., Holsapple, K.A., 1987. Velocity scaling impact melt volume International Journal of Impact Engineering 5, 155-163.

Boyce, J.M., Wilson, L., Mouginis-Mark, PJ., Hamilton, C.W., Tornabene, L.L., 2012. Origin of small pits in martian impact craters. Icarus 221, 262-275.

Bray, V.J, et al., 2010. New insight into lunar impact melt mobility from the LRO camera, Geophysical Research Letters 37, http://dx.doi.org/10.1029/ 2010GL044666.

Buczkowski, D.L., DeSanctis, M.C., Raymond, C.A., Wyrick, D.Y., Williams, D.A., Russell, C.T., 2013. Brumalia Tholus: An indication of magmatic intrusion on Vesta?, Abstract \#1996, Lunar and Planetary Science XLIV, Lunar and Planetary Institute, Houston (CD-ROM)

Carr, M.H., Crumpler, L.S., Cutts, J.A., Greeley, R., Guest, J.E., Masursky, H., 1977. Martian impact craters and emplacement of ejecta by surface flow. Journal of Geophysical Research 82 (4), 055-4,065.

Carr, M.H., Kirk, R.L., McEwen, A., Veverka, J., Thomas, P., Head, J.W., Murchie, S. 1994. The geology of Gaspra. Icarus 107, 61-71.

Carter, L.M., Neish, C.D., Bussey, D.B.J., Spudis, P.D., Patterson, G.W., Cahill, J.T. Raney, R.K., 2012. Initial observations of lunar impact melts and ejecta flows with the Mini-RF radar. Journal of Geophysical Research 117, E00H09, http://dx doi.org/10.1029/2011JE003911.

Chapman, C.R., Merline, W.J., Thomas, P.C., Joesph, J., Cheng, A.F. Izenberg, N., 2002 Impact history of Eros: craters and boulders. Icarus 155, 104-118.

Cochran, A.L., Villas, F., 1998. The changing spectrum of Vesta: rotationally resolved spectroscopy on surface. Icarus $134,207-212$.

Croft, S. K. (1985). The scaling of complex craters. In: G. Ryder and G. Schubert, (Eds.), Lunar and Planetary Science Conference Proceedings, volume 15 of Lunar and Planetary Science Conference Proceedings. pp. 828.

Davison, T.M., Collins, G.S., Ciesla, F.J., 2010. Numerical modelling of heating in porous planetesimal collisions. Icarus 208, 468-481.

Davison, T. M., D. P. O'Brien, Ciesla, F. J. Collins, G. S. (2013). The impact histories of meteorite parent bodies. In preparation.

Dence, M.R., 1971. Impact melts. Journal of Geophysical Research 76 (5), http://dx doi.org/10.1029/JB076i023p05552 552-5,565

Denevi, B.W., Koeber., S.D., Robinson, M.S., Garry, W.B., Hawke, B.R., Tran, T.N Lawrence, S.J., Keszthelyi, L.P., Barnouin, O.S., Ernst, C.M., Tournabene, L.L, 2012. Physical constraints on impact melt properties from Lunar Reconnaissance Orbiter Camera images. Icarus 219, 665-675.

De Sanctis, M.C. Coradini, A. Ammannito, E. Filacchione, G., Capria, M.T, Fonte, S Magni, G., Barbis, A., Bini, A., Dami, M., Ficai-Veltroni, I., Preti, G., Team, VIR, 2011. The VIR Spectrometer. Space Science Reviews 163, 329-370.

De Sanctis, M.C., Ammannito, E., Capria, M.T., Tosi, F., Capaccioni, F., Zambon, F. Carraro, F, Fonte, S., Frigeri, A Jaumann, R, Magni, G., Marchi, S., McCord, T.B. McFadden, L.A., McSween, H.Y., Mittlefehldt, D.W., Natheus, A., Palomba, E., Pieters, C.M., Raymond, C.A., Russell, C.T., Toplis, M.J., Turrini, D., 2012. Spectroscopic characterization of mineralogy and its diversity across Vesta. Science 336, 697-700.
Feierberg, M.A., Larson, H.P., Fink, U., Smith, H.A., 1980. Spectroscopic evidence for two achondrite parent bodies: asteroid 349 Dembowska and 4 Vesta. Geochimica et Cosmochimica Acta 44, 513-524.

Gaffey, M.J., 1997. Surface lithologic heterogeneity of asteroid 4 Vesta. Icarus 127, 130-157.

Gault, D.E., 1974. Impact cratering. In: Greeley, R., Schultz, P.H. (Eds.), A Primer in Lunar Geology. NASA Ames Research Center, Mountain View, CA, pp. 137-175.

Gilbert, G.K., 1893. The Moon's face: a study of the origin of its features. Bulletin of the Philosophical Society Washington, 241-292.

Hawke, B.R., Head, J.W., 1977. Impact melt on lunar crater rims, Impact and Explosion Cratering: Planetary and Terrestrial Implications. Pergamon Press, New York, pp. 815-841.

Howard, K.A., Wilshire, H.G., 1975. Flows of impact melt at lunar craters. Journal of Research of the US Geological Survey 3, 237-251.

Ivanov, B.A., Hartmann, W.K., 2007. Exogenic dynamics, cratering and surface ages. In: Spohn, T. (Ed.), Treatise on Geophysics, 10. Elsevier, pp. 207-242.

Ivanov, B.A., 2001. Mars/Moon cratering rate ratio estimates. Space Science Reviews 96, 87-104.

Jaumann, R., et al., 2012. Vesta's shape and morphology. Science 336, 687-690.

Keil, K., 2002. Geological history of asteroid 4 Vesta: the "smallest terrestrial planet". In: Bottke Jr., W.F., Cellino, A, Paolicchi, P., Binzel, R.P. (Eds.), Asteroids III. University of Arizona Press, Tucson, pp. 573-584.

Keil, K., Wilson, L., 2012. Volcanic eruption and intrusion processes on 4 Vesta: a Reappraisal, Lunar and Planetary Science XLIII. Lunar and Planetary Institute, Houston (CR-ROM), Abstract \#1127.

Keil, K., Stoeffler, D., Love, S.G., Scott, E.R.D., 1997. Constraints on the role of impact heating and melting in asteroids. Meteoritics and Planetary Science 32, 349-363.

Krohn, K.,R. Jaumann, D. Elbeshausen, T. Kneissl, S. Schröder, R. Wagner, K. Stephan, K. Otto, K.D. Matz, F. Preusker, T. Roatsch, N. Schmedemann, C.A. Raymond, C.T. Russell. Asymmetric craters on Vesta: impact on sloping surfaces,, Planetary and Space Science., this issue.

Massironi, M., Marchi, S., Pajola, M., Snodgrass, C., Thomas, N., Tubiana, C., Vincent, J.-B., Cremonese, G., Da Deppo, V., Ferri, F., Magrin, S., Sierks, H., Barbieri, C., Lamy, P., Rickman, H., Rodrigo, R., Koschny, D., 2012. the OSIRIS Team, 2012. Geological map and stratigraphy of asteroid 21 Lutetia. Planetary and Space Science 66, 125-136.

McCord, T.B., Adams, J.B., Johnson, T.V., 1970. Asteroid Vesta: spectral reflectivity and compositional implications. Science 168, 1445-1447.

McCord, T.B., Li, J.-Y., Combe, J.-Ph., McSween, H.Y., Jaumann, R., Reddy, V., Tosi, F., Williams, D.A., Blewett, D.T., Turrini, D., Palomba, E., Pieters, C.M., De Sanctis, M. C. Ammannito, E Capria, MT, Le Corre, L, Longobardo, A Nathues, A. Mittlefehldt, D.W., Schröder, S.E., Hiesinger, H., Beck, A.W., Capaccioni, F., Carsenty, U., Keller, H.U., Denevi, B.W., Sunshine, J.M., Raymond, C.A., Russell, C.T. 2012. Dark Material on Vesta from the infall of carbonaceous volatile-rich material. Nature 491, 83-86, http://dx.doi.org/10.1038/nature11561.

McSween Jr., H.Y., Mittlefehldt, D.W., Beck, A.W., Mayne, R.G., McCoy, T.J., 2011. HED meteorites and their relationship to the geology of Vesta and the Dawn Mission. Space Science Reviews 163, 141-174.

McSween, H.Y., Ammannito, E., Reddy, V., Prettyman, T., Beck, A.W., De Sanctis, M. C., Nathues, A., Le Corre, L., O'Brien, D.P., Yamashita, N., McCoy, T.J., Mittlefehldt, D.W., Toplis, M.J., Schenk, P., Palomba, E., Turrini, D., Tosi, F., Zambon, F., Longobardo, A., Capaccioni, F., Raymoind, C.A., Russell, C.T., 2013. Composition of the Rheasilvia basin, a window into Vesta's interior. Journal of Geophysical Research 118, 335-346, http://dx.doi.org/10.1002/jgre.200057.

McSween, H.Y., Jr., et al., Vesta-HED connection and geologic context for HEDs, Meteoritics \& Planetary Science., in press.

Melosh, H.J., 1989. Impact Cratering: A Geologic Process. Oxford University Press.

O'Brien, D.P., Sykes, M.V., 2011. The origin and evolution of the asteroid belt-implications for Vesta and Ceres. Space Science Reviews 163, 41-61.

O'Keefe, J. D. Ahrens, T. J. (1977). Partitioning of energy and the degree of melting and vaporization in planetary impact processes. In: Lunar and Planetary Institute Science Conference Abstracts, volume 8 of Lunar and Planetary Institute Science Conference Abstracts, pp. 741.

Osinski, G.R., Tornabene, L.L., Grieve, R.A.F., 2011. Impact ejecta emplacement on terrestrial planets. Earth and Planetary Science Letters 310, 167-181.

Otto, K., Jaumann, R., Krohn, K., Matz, K.-D., O'Brien, D.P., Preusker, F., Roatsch, T. Schenk, P., Stephan, K., Raymond, C.A., Russell, C.T., 2013. Mass wasting features in Vesta's south polar basin Rheasilvia, Journal of Geophysical Research, in review.

Pierazzo, E., Melosh, H.J., 2000. Melt production in oblique impacts. Icarus 145, $252-261$.

Pierazzo, E., Vickery, A.M., Melosh, H.J., 1997. A reevaluation of impact melt production. Icarus $127,408-423$.

Pike, R.J. (1976). Simple to complex impact craters: the transition on the Moon. In: Lunar and Planetary Institute Science Conference Abstracts, pp. 700-702.

Plescia, J.B., Cintala, M.J., 2012. Impact melt in small lunar craters. Journal of Geophysical Research 117, E00H12, http://dx.doi.org/10.1029/2011JE003941.

Reddy, V., 2012. and 24 coauthors, 2012. Delivery of dark material to Vesta via carbonaceous chondritic impacts. Icarus 221, 544-559.

Righter, K., Drake, M.J., 1997. A magma ocean on Vesta: core formation and petrogenesis of eucrites and diogenites. Meteoritics \& Planetary Science 32, 929-944.

Ruzicka, A., Snyder, G.A., Taylor, L.A., 1997. Vesta as the howardite, eucrite, and diogenite parent body: implications for the size of a core and for large-scale differentiation. Meteoritics \& Planetary Science 32, 825-840. 
Russell, C.T., Raymond, C.A., Coradini, A., McSween, H.Y., Zuber, M.T., Nathues, A., De Sanctis, M.C., Jaumann, R., Konopliv, A.S., Preusker, F., Asmar, S.W., Park, R.S., Gaskell, R., Keller, H.U., Mottola, S., Roatsch, T., Scully, J.E.C., Smith, D.E., Tricarico, P., Toplis, M.J., Christensen, U.R., Feldman, W.C., Lawrence, D.J., McCoy, T.J., Prettyman, T.H., Reedy, R.C., Sykes, M.E., Titus, T.N., 2012. Dawn at Vesta: testing the Protoplanetary Paradigm. Science 336, 684-686.

Schenk, P.M., O'Brien, D.P., Marchi, S., Gaskell, R., Preusker, F., Roatsch, T., Jaumann, R., Buczkowski, D., McCord, T., McSween, H.Y., Williams, D., Yingst, A., Raymond, C., Russell, C., 2012. The geologically recent giant impact basins at Vesta's south pole. Science 336, 694-697.

Schenk, P.M., et al., Impact crater morphology on Vesta, Planetary and Space Science., in preparation.

Schiller, M., Baker, J.A., Bizzarro, M., 2010. 26Al-26Mg dating of asteroidal magmatism in the young solar system. Geochimica et Cosmochimica Acta 74, 4844-4864.

Schmidt, R.M., Housen, K.R., 1987. Some recent advances in the scaling of impact and explosion cratering. International Journal of Impact Engineering 5, 543-560.

Shoemaker, E.M., 1962. Interpretation of lunar craters. In: Kopal, Z. (Ed.), Physics and Astronomy of the Moon. Academic Press, New York, pp. 283-351.

Sierks, H., Keller, H.U., Jaumann, R., Michalik, H., Behnke, T., Bubenhagen, F., Büttner, I., Carsenty, U., Christensen, U., Enge, R., Fiethe, B., Gutiérrez Marqués, P., Hartwig, H., Krüger, H., Kühne, W., Maue, T., Mottola, S., Nathues, A., Reiche, K.-U., Richards, M.L., Roatsch, T., Schröder, S.E., Szemercy, |widehat., Tschentscher, M., 2011. The Dawn Framing Camera. Space Science Reviews $163,263-328$.

Sullivan, R.J., Thomas, P.C., Murchie, S.L., Robinson, M.S., 2002. Asteroid geology from Galileo and NEAR Shoemaker data. In: Bottke Jr., W.F., Cellino, A., Paolicchi,
P., Binzel, R.P. (Eds.), Asteroids III. University of Arizona Press, Tucson, pp. 331-350.

Thomas, P.C., Binzel, R.P., Gaffey, M.J., Storrs, A.D., Wells, E.N., Zellner, B.H., 1997 Impact excavation on asteroid 4 Vesta: Hubble Space Telescope results. Science 277, 1492-1495.

Tornabene, L.L., Osinski, G.R., McEwen, A.S., Boyce, J.M., Bray, V.J., Caudill, C.M., Grant, J.A., Hamilton, C.W., Mattson, S., Mouginis-Mark, P.J., 2012. Widespread crater-related pitted materials on Mars: further evidence for the role of target volatiles during the impact process. Icarus 220, 348-368.

Warren, P.H., 1997. Magnesium oxide-iron oxide mass balance constraints and a more detailed model for the relationship between eucrites and diogenites. Meteoritics \& Planetary Science 32, 945-963.

Wieczorek, M.A., et al., 2013. The Crust of the Moon as Seen by GRAIL. Science 339 671-675.

Williams, D.A., B.W. Denevi, D.W. Mittlefehldt, S.C. Mest, P.M. Schenk, R.A. Yingst, D. L. Buczkowski, J.E.C. Scully, W.B. Garry, T.B. McCord, J.-Ph. Combe, R. Jaumann, C. M. Pieters, A. Nathues, L. Le Corre, M. Hoffmann, V. Reddy, T. Roatsch, F. Preusker, S. Marchi ,T. Kneissl, G. Neukum, N. Schmedemann, H. Hiesinger, M.C. De Sanctis, E. Ammannito, A. Frigeri, T.H. Prettyman, C.T. Russell, C.A. Raymond, the Dawn Science Team, The Geology of the Marcia Quadrangle of Asteroid Vesta: Assessing the Effects of Large, Young Craters, Icarus, in review.

Wilson, L., Keil, K., 1996. Volcanic eruptions and intrusions on asteroid 4 Vesta. Journal of Geophysical Research 101 (18), 927-18,940.

Wilson, L., Keil, K., 1997. The fate of pyroclasts produced in explosive eruptions on the asteroid 4 Vesta. Meteoritics \& Planetary Science 32, 813-823.

Wünnemann, K., Collins, G.S., Osinski, G.R., 2008. Numerical modeling of impact melt production in porous rocks. Earth and Planetary Science Letters 269, 530-539. 